\title{
Adsorption Mechanism of Typical Gases Exhaled by Lung Cancer Patients on the Anatase $\mathrm{TiO}_{2}$ (101) Surface
}

\author{
Qianqian Wan $\mathbb{D}^{1},{ }^{1}$ Yancheng $X u \mathbb{D}^{1},{ }^{1}$ and Xiaoxing Zhang $\mathbb{D}^{2,3}$ \\ ${ }^{1}$ Zhongnan Hospital of Wuhan University, Wuhan, Hubei, China \\ ${ }^{2}$ School of Electrical Engineering, Wuhan University, Wuhan, Hubei, China \\ ${ }^{3}$ State Key Laboratory of Power Transmission Equipment \& System Security and New Technology, Chongqing University, \\ Chongqing 400044, China
}

Correspondence should be addressed to Yancheng Xu; xj1100901@whu.edu.cn

Received 12 August 2017; Revised 27 October 2017; Accepted 28 November 2017; Published 9 January 2018

Academic Editor: Giorgio Pennazza

Copyright @ 2018 Qianqian Wan et al. This is an open access article distributed under the Creative Commons Attribution License, which permits unrestricted use, distribution, and reproduction in any medium, provided the original work is properly cited.

\begin{abstract}
Considerable researches have proved that, to a great extent, high death rate of lung cancer is on account of its crypticity in the early stage, and detection of typical exhaled gases of possible patients has emerged as an effective and workable method to realize the prognosis of lung cancer. In this paper, the adsorption of the three typical exhaled components, namely, $\mathrm{C}_{6} \mathrm{H}_{6}, \mathrm{C}_{8} \mathrm{H}_{8}$, and $\mathrm{C}_{5} \mathrm{H}_{8}$, of lung cancer patients on the anatase $\mathrm{TiO}_{2}$ (101) surface was simulated based on the density functional theory method in order to recommend $\mathrm{TiO}_{2}$ nanotube arrays as sensing materials to fulfill this aim. Analysis based on adsorbing parameters, frontier molecular orbital theory, and density of states congruously implies that the anatase $\mathrm{TiO}_{2}(101)$ surface possesses certain sensitivity to these three gases, especially to $\mathrm{C}_{8} \mathrm{H}_{8}$ which possesses the best activity to be adsorbed on the proposed surface. Our experimental study showed great consensus with the theoretical calculations. Therefore, $\mathrm{TiO}_{2}$ nanotube arrays can be applied as proper gas-sensing material for the preparation of lung cancer prognosis sensors as a family device to realize the simple and convenient detection of lung cancer in our daily life.
\end{abstract}

\section{Introduction}

Lung cancer is one of the most threatening malignances to human health and lives with the largest increasing rate of incidence and death. On the other hand, some drawbacks of current clinical examination devices for lung cancer such as high price, complicated operation steps, and long detective duration make them really impossible to be conducted for a patient in a poor family or some businessmen without that time [1-4]. What is worse is that usually, clinical examinations can only be carried out when patients feel out of sorts, and frequently these groups miss the best time for cure of lung cancer in the early period. Therefore, it is of great significance to exploit and prepare some novel detecting devices with convenient preparation technics, quick response, long lifetime, and low price, in order to realize the detection and prognosis of lung cancer.

There are numerous typical markers of lung cancer for its detection. Clinically, characteristic markers of blood serum are commonly used for the detection of lung cancer. Simply, the exhaled air can provide many information about people's health in terms of lung cancer, providing possible approaches for the preparation of portable detecting devices. The idea that exhaled gas could be applied for diagnosis of lung cancer was proposed at the earliest by Gordon in 1985. Gordon's group selected 22 kinds of volatile organic compounds (VOCs) in total, which are considered the characteristic contents in exhaled air of lung cancer patients, mainly the derivatives of alkane and benzene [5]. Phillips's group has been devoted to the detection of typical VOCs in exhaled air of lung cancer patients all the time since 1999 and came up with 22 types of characteristic VOCs of lung cancer, including benzene $\left(\mathrm{C}_{6} \mathrm{H}_{6}\right)$, styrene $\left(\mathrm{C}_{8} \mathrm{H}_{8}\right)$, and isoprene $\left(\mathrm{C}_{5} \mathrm{H}_{8}\right)[6]$.

As a new kind of sensing material in the gas-sensing field, $\mathrm{TiO}_{2}$ nanotube arrays (TNTAs) possess good physicochemical properties like adjustable size, large specific surface area, simple preparation method, and strong adsorption and desorption ability to gas molecules. Gas sensors made of 


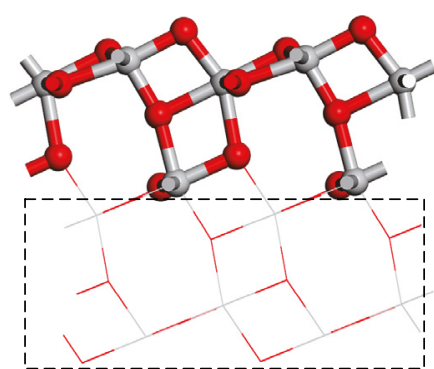

(a)

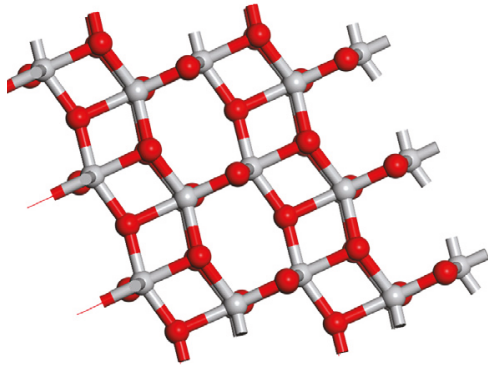

(b)

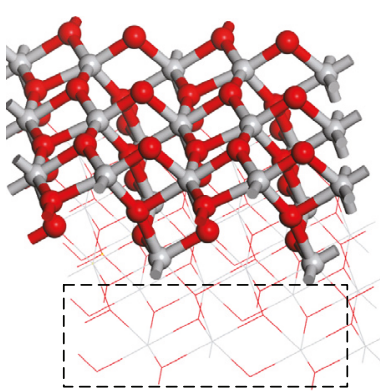

(c)

Figure 1: Structure of the anatase $\mathrm{TiO}_{2}$ (101) surface. (a) Top view, (b) front view, and (c) side view.

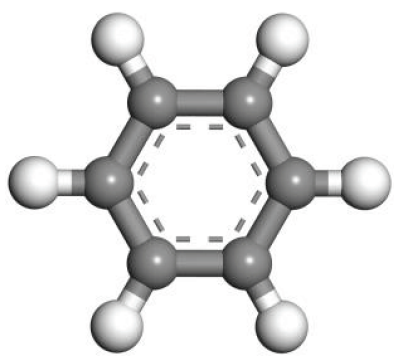

(a)

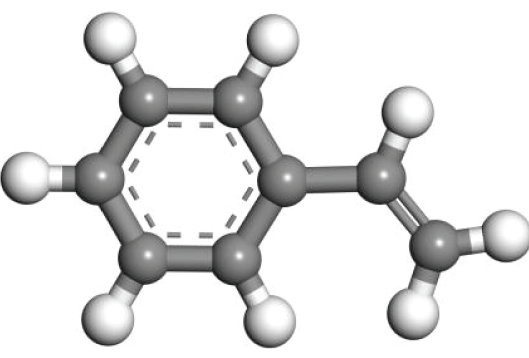

(b)

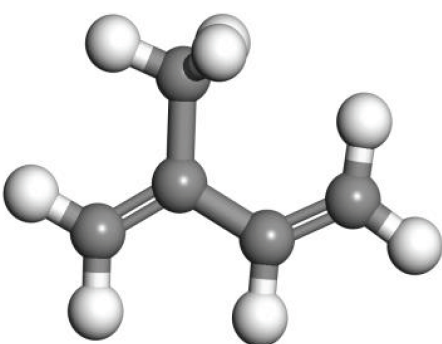

(c)

Figure 2: Structure of typical gas molecules of lung cancer. (a) Benzene, (b) styrene, and (c) isoprene.

TNTAs have benefits like quick response, high sensitivity, and high stability. The gas-sensing performances of such sensors can be enhanced by metal and nonmetal doping and, at the same time, realize the selective detection towards the components and contents of mixed gases [7-11]. In recent years, researches of TNTA gas sensors focus on the detection of some common gases such as $\mathrm{CO}, \mathrm{H}_{2}, \mathrm{O}_{2}, \mathrm{NH}_{3}, \mathrm{NO}_{2}$, acetone, and ethanol [12-17], while, to the best of our knowledge, there are few reports about the application of TNTAs for the prognosis of lung cancer through the detection of some VOCs.

In this paper, based on the density function (DFT) theory, the adsorption of benzene $\left(\mathrm{C}_{6} \mathrm{H}_{6}\right)$, styrene $\left(\mathrm{C}_{8} \mathrm{H}_{8}\right)$, and isoprene $\left(\mathrm{C}_{5} \mathrm{H}_{8}\right)$ on the anatase $\mathrm{TiO}_{2}(101)$ surface was carried out by simulation software of Materials Studio [18] in order to understand the adsorption mechanism of these three gases on the $\mathrm{TiO}_{2}$ surface, giving rise to the basic knowledge for the future application of such sensing materials upon lung cancer prognosis. Adsorption behaviors of these three molecules and the effect of molecule adsorption on the characteristics of the $\mathrm{TiO}_{2}$ (101) surface were analyzed. The related experiment was carried as well to confirm our theoretical results. Our calculations and experiment are meaningful because they can provide theoretical foundation for future preparation and applications of TNTA gas biosensors as a family device for practical application in the field of lung cancer prognosis.

\section{Simulation Model and Calculation Method}

The structural model of the anatase $\mathrm{TiO}_{2}$ (101) surface was constructed using periodic boundary, with the size of
$10.88 \times 11.32 \times 24.35 \AA$ [3]. A vacuum layer of $16 \AA$ high above the surface was also built to avoid the interactions between crystal surfaces caused by periodic boundary. Figure 1 shows the views of the anatase $\mathrm{TiO}_{2}$ (101) surface model from different angles. During structural optimization, bottom half atoms in the structure were fixed without optimization (shown by a linear model) while the top half atoms in the structure were optimized (shown by a ball-and-stick model). Figure 2 shows the structural models of the three kinds of molecules including benzene $\left(\mathrm{C}_{6} \mathrm{H}_{6}\right)$, styrene $\left(\mathrm{C}_{8} \mathrm{H}_{8}\right)$, and isoprene $\left(\mathrm{C}_{5} \mathrm{H}_{8}\right)$. Both the gas molecules and the $\mathrm{TiO}_{2}$ models were geometrically optimized for proceeding the adsorption processes. Referring to establishing the adsorption configurations, the three kinds of gas molecules are approaching to the anatase $\mathrm{TiO}_{2}$ (101) surface from different positions and angles, followed by constant optimization. As a result, relatively stable structures of the three kinds of molecules adsorbed on the anatase $\mathrm{TiO}_{2}$ (101) surface were obtained, as shown in Figure 3.

Details of the calculation method should be noted as follows: generalized gradient approximation (GGA) associated with Perdew-Burke-Ernzerhof (PBE) was employed to deal with the exchange-correlation function among electrons. The double numerical basis set plus polarization (DNP) functions were also adopted [16]. Energy convergence was set as $1.0 \times 10^{-5} \mathrm{Ha}$, with energy gradient and atom displacement as $0.002 \mathrm{Ha} / \AA$ and $0.005 \AA$, respectively. In order to improve the convergence rate and reduce the calculation time, the convergence threshold of the electronic self-consistent field was set as $1.0 \times 10^{-6} \mathrm{Ha}$. Besides, the calculation was carried out using DIIS with smearing set as $5.0 \times 10^{-4} \mathrm{Ha}$. k-mesh of the calculation model was 

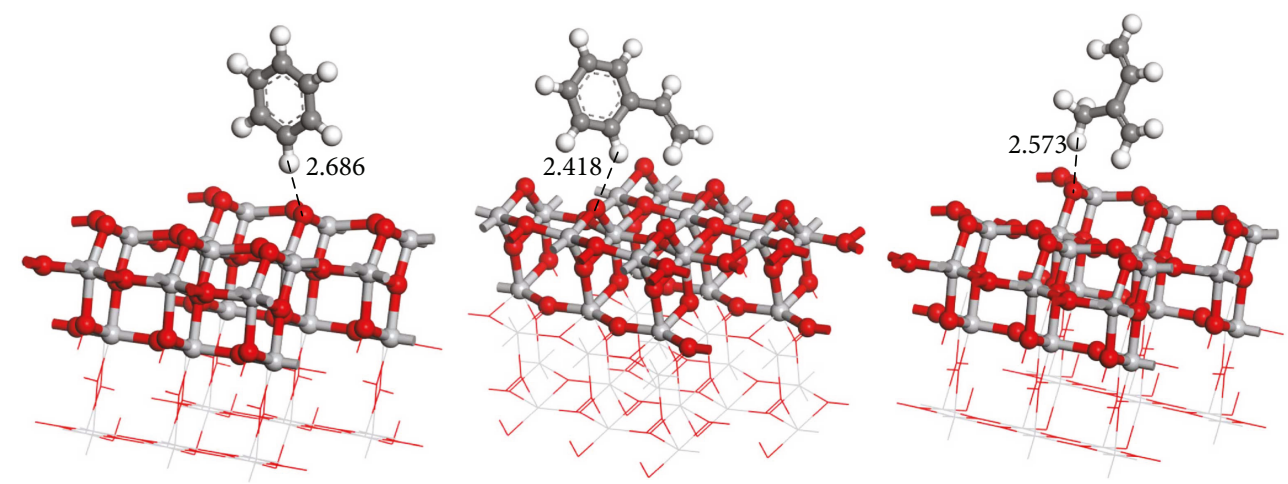

FIgURE 3: Adsorption configurations of benzene, styrene, and isoprene on the anatase $\mathrm{TiO}_{2}(101)$ surface.

$2 \times 2 \times 1$ [19]. All calculations were implemented in the DMol [3] package.

\section{Results and Discussion}

In order to reflect the spontaneity of interactions between the anatase $\mathrm{TiO}_{2}$ (101) surface and gas molecules, the adsorption energy $\left(E_{\text {ad }}\right)$ was defined as follows:

$$
E_{\text {ad }}=E_{\text {sur+molecule }}-E_{\text {molecule }}-E_{\text {sur }} \text {, }
$$

where $E_{\text {molecule }}$ is the energy of the individual gas molecule, $E_{\text {sur }}$ is the energy of the insolated anatase $\mathrm{TiO}_{2}(101)$ surface, and $E_{\text {sur-molecule }}$ is the total energy of the anatase $\mathrm{TiO}_{2}(101)$ surface model after gas molecule adsorption.

If $E_{\mathrm{ad}}<0$, the adsorption is exothermic and spontaneous and the larger the absolute value, the more drastic the adsorption function. Otherwise, if $E_{\mathrm{ad}}$ is smaller than 0 , it indicates that the interaction cannot occur.

Moreover, to illustrate the change of charge distribution before and after the adsorption of gas molecules on the anatase $\mathrm{TiO}_{2}$ (101) surface, Mulliken population analysis was conducted, which is important because it can quantitatively present the charge transfer number and qualitatively determine the charge transferring path between the gas molecule and $\mathrm{TiO}_{2}$ (101) surface. Charge transfer $(q)$ represents the carried charge value of gas molecules in the adsorbed systems. The calculation result that $q>0$ indicates electron transfers from the gas molecule to anatase $\mathrm{TiO}_{2}$ (101) surface, while the negative value of $q$ represents the converse electron transferring path. Adsorption distance $(D)$ is the nearest distance between the anatase $\mathrm{TiO}_{2}$ (101) surface and any atom of the gas molecule in the adsorption system. Table 1 lists the adsorption energy, charge transfer, and adsorption distance of three stable adsorption structures in terms of the anatase $\mathrm{TiO}_{2}$ (101) surface and benzene $\left(\mathrm{C}_{6} \mathrm{H}_{6}\right)$, styrene $\left(\mathrm{C}_{8} \mathrm{H}_{8}\right)$, and isoprene.

According to the negative values of $E_{\mathrm{ad}}$ shown in Table 1, it can be inferred that the adsorption processes of the three gas molecules on the anatase $\mathrm{TiO}_{2}(101)$ surface are exothermic and spontaneous, which indicates the feasibility of interactions between the novel surface and these gases. However, all the small values agree that the adsorption processes of the three gases are closer to physical adsorption rather than to
TABLE 1: Adsorbing parameters of the three adsorbed systems.

\begin{tabular}{lccc}
\hline Systems & $\begin{array}{c}\text { Adsorption energy } \\
\left(E_{\mathrm{ad}}\right)(\mathrm{eV})\end{array}$ & $\begin{array}{c}\text { Charge } \\
\text { transfer }(q)(\mathrm{e})\end{array}$ & $\begin{array}{c}\text { Adsorption } \\
\text { distance }(D)(\AA)\end{array}$ \\
\hline $\mathrm{C}_{6} \mathrm{H}_{6}$ & -0.5641 & 0.054 & 2.686 \\
$\mathrm{C}_{8} \mathrm{H}_{8}$ & -0.6949 & 0.142 & 2.418 \\
$\mathrm{C}_{5} \mathrm{H}_{8}$ & -0.6056 & 0.114 & 2.573 \\
\hline
\end{tabular}

chemical adsorption. Comparison of $E_{\text {ad }}$ among the three systems indicates that the adsorption energy of $\mathrm{C}_{8} \mathrm{H}_{8}$ is the largest and thereby the interaction between $\mathrm{C}_{8} \mathrm{H}_{8}$ and the anatase $\mathrm{TiO}_{2}$ (101) surface is relatively stronger with more stable adsorption structure than that of the other two adsorption processes. This result signifies that the $\mathrm{TiO}_{2}$ surface may possess the most sensitivity to $\mathrm{C}_{8} \mathrm{H}_{8}$ compared with the other two typical components. Apart from that, it can be found that the largest value of $q$ and the shortest value of $D$ among the three systems are numerically in agreement with the $E_{\text {ad }}$ order, namely, demonstrating the superior sensitivity of the $\mathrm{TiO}_{2}$ surface to the $\mathrm{C}_{8} \mathrm{H}_{8}$ molecule. All the positive values of $q$ imply that the charge transfers from the gas molecules to the $\mathrm{TiO}_{2}$ surface, suggesting that the gas molecules perform as the electron donor while the $\mathrm{TiO}_{2}$ surface as the electron acceptor. As clearly seen in Table 1 , the $q$ values in terms of the three systems are in order as $\mathrm{C}_{8} \mathrm{H}_{8}>\mathrm{C}_{5} \mathrm{H}_{8}>\mathrm{C}_{6} \mathrm{H}_{6}$, which are in good consensus with the orders of $E_{\text {ad }}$ and $D$. It can be further concluded that charge transfer from $\mathrm{C}_{8} \mathrm{H}_{8}$ to the anatase $\mathrm{TiO}_{2}$ (101) surface is slightly larger than that of $\mathrm{C}_{5} \mathrm{H}_{8}$ and the last system; charge transfer value is almost twice as many as that of $\mathrm{C}_{6} \mathrm{H}_{6}$. Therefore, $\mathrm{C}_{8} \mathrm{H}_{8}$ that provides more electrons for the anatase $\mathrm{TiO}_{2}$ (101) surface can lead to better sensitivity in its sensing interaction.

In order to determine the effect of gas adsorption on the conductivity of the proposed $\mathrm{TiO}_{2}$ material after adsorbing typical gases of lung cancer patients on its surface, the frontier molecular orbital theory was conducted. Through analyzing the change of energy gap $\left(E_{\mathrm{g}}\right)$ of the adsorbed system compared with the pure $\mathrm{TiO}_{2}$ system, related conclusion can be drawn, because $E_{\mathrm{g}}$ is a quite significant parameter for bulk materials to measure their conductivity according to previous reports $[9,20]$. Based on the frontier molecular orbital theory, energy levels of the highest occupied molecular orbital (HOMO) and the lowest unoccupied molecular 
TABle 2: Energy of the anatase $\mathrm{TiO}_{2}$ (101) surface and three gas molecules.

\begin{tabular}{lcccc}
\hline Calculation system & $E_{\text {HOMO }}(\mathrm{eV})$ & $E_{\text {LUMO }}(\mathrm{eV})$ & $E_{1}(\mathrm{eV})$ & $E_{2}(\mathrm{eV})$ \\
\hline $\mathrm{TiO}_{2}$ & -0.2749 & -0.2033 & - & - \\
$\mathrm{C}_{6} \mathrm{H}_{6}$ & -0.2204 & -0.0287 & 0.2462 & 0.0171 \\
$\mathrm{C}_{8} \mathrm{H}_{8}$ & -0.1973 & -0.0601 & 0.2148 & 0.0041 \\
$\mathrm{C}_{5} \mathrm{H}_{8}$ & -0.1980 & -0.0515 & 0.2234 & 0.0053 \\
\hline
\end{tabular}

TABLE 3: Energy gap of $\mathrm{TiO}_{2}$ and the three adsorption structures.

\begin{tabular}{lccc}
\hline Calculation system & $E_{\text {HOMO }}(\mathrm{eV})$ & $E_{\text {LUMO }}(\mathrm{eV})$ & $E_{\mathrm{g}}(\mathrm{eV})$ \\
\hline $\mathrm{TiO}_{2}$ & -7.480 & -5.532 & 1.948 \\
$\mathrm{TiO}_{2}-\mathrm{C}_{6} \mathrm{H}_{6}$ & -6.599 & -5.488 & 1.110 \\
$\mathrm{TiO}_{2}-\mathrm{C}_{8} \mathrm{H}_{8}$ & -6.207 & -5.432 & 0.775 \\
$\mathrm{TiO}_{2}-\mathrm{C}_{5} \mathrm{H}_{8}$ & -6.215 & -5.393 & 0.824 \\
\hline
\end{tabular}

orbital (LUMO) of the pure anatase $\mathrm{TiO}_{2}$ (101) surface and three individual molecules were calculated, respectively. Through comparing the energy level of HOMO and LUMO of the anatase $\mathrm{TiO}_{2}$ (101) surface with that of the gas molecules, the difficult level of charge transfer between the three gases and anatase $\mathrm{TiO}_{2}$ (101) surface can be judged, where $E_{1}$ and $E_{2}$ are defined as the following:

$$
\begin{aligned}
& E_{1}=\left|E_{\mathrm{HOMO}\left(\mathrm{TiO}_{2}\right)}-E_{\mathrm{LUMO}(\mathrm{gas})}\right|, \\
& E_{2}=\left|E_{\mathrm{LUMO}\left(\mathrm{TiO}_{2}\right)}-E_{\mathrm{HOMO}(\mathrm{gas})}\right| .
\end{aligned}
$$

The smaller $E_{1}$ is, the easier it is for electrons to transfer from the anatase $\mathrm{TiO}_{2}$ (101) surface to gas molecules; the smaller $E_{2}$ is, the easier it is for electrons to transfer from the gas molecules to anatase $\mathrm{TiO}_{2}$ (101) surface. $E_{\mathrm{HOMO}}$, $E_{\mathrm{LUMO}}, E_{1}$, and $E_{2}$ of the three gas molecules and anatase $\mathrm{TiO}_{2}$ (101) surface are shown in Table 2.

As can be concluded from Table 2, $E_{1}$ and $E_{2}$ of $\mathrm{C}_{8} \mathrm{H}_{8}$ are the smallest among the three gas molecules, which states that the adsorption function and charge transfer between $\mathrm{C}_{8} \mathrm{H}_{8}$ and the anatase $\mathrm{TiO}_{2}$ (101) surface are easiest to happen. That is to say, the anatase $\mathrm{TiO}_{2}$ (101) surface has the highest sensitivity to $\mathrm{C}_{8} \mathrm{H}_{8}$ and $\mathrm{C}_{5} \mathrm{H}_{8}$ takes the second place. These results are in agreement with those of our previous analysis in terms of $E_{\mathrm{ad}}, D$, and $q$.

The energy gap $\left(E_{\mathrm{g}}\right)$ of the adsorbing systems before and after adsorption can also be obtained based on energies of HOMO and LUMO, which is defined as follows with the calculated $E_{\mathrm{g}}, E_{\mathrm{HOMO}}$, and $E_{\mathrm{LUMO}}$ for the insolated $\mathrm{TiO}_{2}$ surface in parallel with the adsorbed systems shown in Table 3.

$$
E_{g}=\left|E_{\mathrm{HOMO}}-E_{\mathrm{LUMO}}\right| \text {. }
$$

Energy gap determines the difficult degree for electrons to transfer from HOMO to LUMO, and it also reflects the ability for electrons to jump from the valence band to conduction band. As can be found from Table 3, the energy gap of the anatase $\mathrm{TiO}_{2}$ (101) surface dropped from $1.948 \mathrm{eV}$ to $1.110 \mathrm{eV}$ after $\mathrm{C}_{6} \mathrm{H}_{6}$ adsorption, to $0.775 \mathrm{eV}$ after
TABLE 4: Energy gap differences of HOMO and LUMO.

\begin{tabular}{llll}
\hline Gas molecule & $\mathrm{C}_{6} \mathrm{H}_{6}$ & $\mathrm{C}_{8} \mathrm{H}_{8}$ & $\mathrm{C}_{5} \mathrm{H}_{8}$ \\
\hline$\Delta E(\mathrm{eV})$ & 5.216 & 3.733 & 3.986 \\
\hline
\end{tabular}

$\mathrm{C}_{8} \mathrm{H}_{8}$ adsorption, and to $0.824 \mathrm{eV}$ after $\mathrm{C}_{5} \mathrm{H}_{8}$ adsorption, which illustrates that the adsorption of the three gas molecules reduced the energy gap of the anatase $\mathrm{TiO}_{2}$ (101) surface and improved the charge transfer ability of the anatase $\mathrm{TiO}_{2}$ (101) surface, causing the electron redistribution in the three systems. Furthermore, given the entire narrowed $E_{\mathrm{g}}$ for the three systems, one can conclude that the conductivity of $\mathrm{TiO}_{2}$ would increase after adsorption of these gases, and moreover, the adsorption of $\mathrm{C}_{8} \mathrm{H}_{8}$ and $\mathrm{C}_{5} \mathrm{H}_{8}$ can bring larger conductive enhancement of the anatase $\mathrm{TiO}_{2}$ (101) surface in comparison with that of the $\mathrm{C}_{6} \mathrm{H}_{6}$ system.

In addition, by comparing the energy gap between $\mathrm{HOMO}$ and LUMO of the gas molecules defined as $\Delta E=$ $E_{\mathrm{LUMO}(\mathrm{gas})}-E_{\mathrm{HOMO}(\mathrm{gas})}$, the active intensity of the gas molecules can be determined as shown in Table 4, which can provide more information from the aspect of the gas molecule itself. We can find that the decreasing order of $\Delta E$ is presented as $\mathrm{C}_{8} \mathrm{H}_{8}>\mathrm{C}_{5} \mathrm{H}_{8}>\mathrm{C}_{6} \mathrm{H}_{6}$, which also represents the activity order of the gas molecules. That is, the $\mathrm{C}_{8} \mathrm{H}_{8}$ has the best activity among the three gases, while $\mathrm{C}_{5} \mathrm{H}_{8}$ was the second and $\mathrm{C}_{6} \mathrm{H}_{6}$ was the last. In the meanwhile, it has been proved that gases with high active intensity are more likely to be adsorbed in a certain surface, without exception of the anatase $\mathrm{TiO}_{2}$ (101) surface. Thus, from this aspect, we found that the $\mathrm{C}_{8} \mathrm{H}_{8}$ would be the most active gas among the three ones to interact with the proposed surface, leading to the large $E_{\mathrm{ad}}$, high $q$, and short $D$. These conclusions inferred from the frontier molecular orbital theory are in accordance with those of the adsorbing parameter analyses.

To further confirm the above conclusions, the density of state (DOS) analysis that can effectively illustrate the electronic behavior and conductivity change of the $\mathrm{TiO}_{2}$ (101) surface before and after adsorption was conducted. Figure 4 shows the total density of state (TDOS) distributions of the insolated $\mathrm{TiO}_{2}$ surface and three adsorbed systems. It can be seen that there exist a wide forbidden band between the valence band and conduction band referring to the insolated anatase $\mathrm{TiO}_{2}$ (101) surface. On the other hand, in the three adsorbed systems, we can find through comparing the TDOS distribution that energy gaps entirely become narrowed due to the new peak emerging between the value band and conduction band. This can be attributed to the adsorption of the gas molecules that leads to the formation of a novel state near the Fermi level [21], and as a consequence, the conductivity of our introduced anatase $\mathrm{TiO}_{2}$ would be enhanced, which is in agreement with the conclusion induced by the frontier molecular orbital theory.

Another common point occurred in DOS of the three adsorbed systems is that all the TDOS curves tend to transform left into a lower region. This is because of the electron-accepting performance of the $\mathrm{TiO}_{2}$ (101) surface [22], and therefore, the anatase $\mathrm{TiO}_{2}$ behaves as an $n$-type semiconductor. In the gas-adsorbing process, electrons 

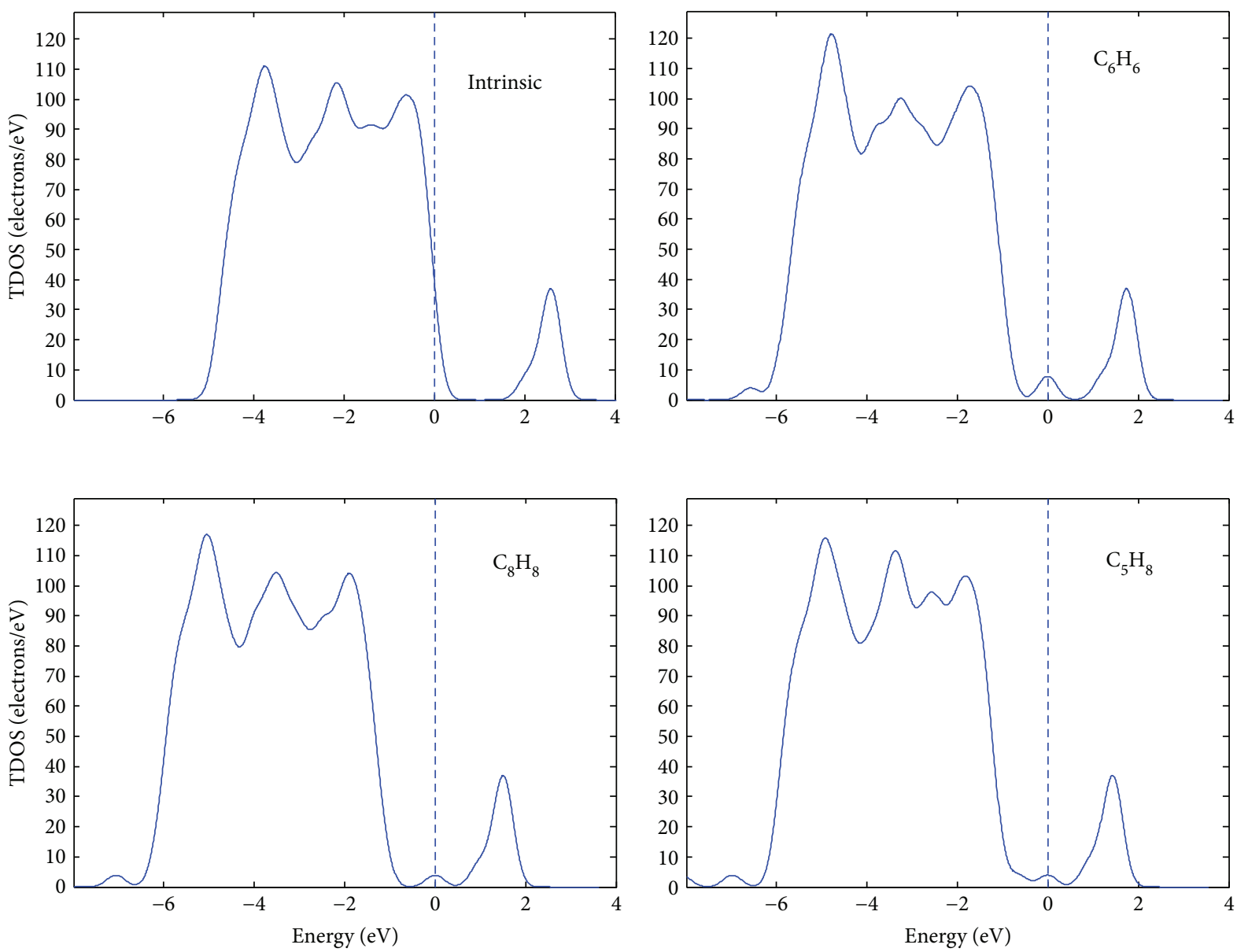

Figure 4: TDOS distributions of the intrinsic $\mathrm{TiO}_{2}(101)$ surface and three adsorbed systems. The dash lines are the Fermi level.

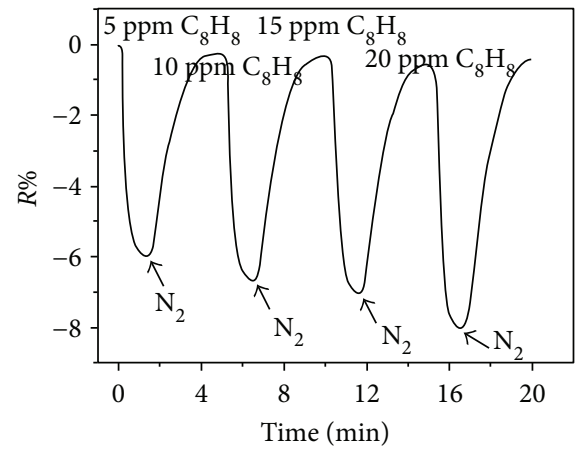

(a)

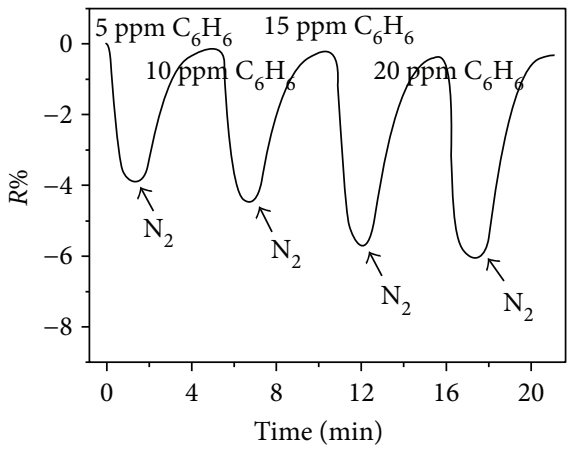

(b)

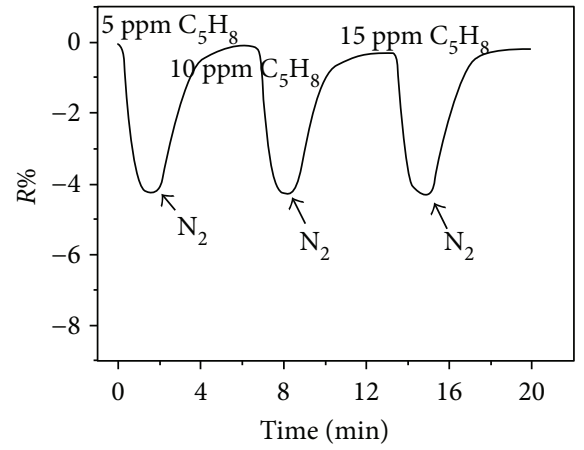

(c)

FIgURE 5: Sensing characteristic of $\mathrm{TiO}_{2}$ towards the three typical gases.

transfer from the gas molecules to the conduction band of the $\mathrm{TiO}_{2}$ surface, improving the carrier density of the proposed semiconductor and thereby boosting the related conductivity.

Overall, according to the previous analyses, we can confirm that the $\mathrm{TiO}_{2}$ surface is able to be a gas adsorbent to interact with the three typical gases of lung cancer patients, namely, $\mathrm{C}_{6} \mathrm{H}_{6}, \mathrm{C}_{8} \mathrm{H}_{8}$, and $\mathrm{C}_{5} \mathrm{H}_{8}$ given their good adsorption performance, and to be promising gas sensors for the prognosis of lung cancer given the conductivity drops of anatase $\mathrm{TiO}_{2}$ when interacted with typical components. On the basis of our calculation results, the anatase $\mathrm{TiO}_{2}$ would be a workable material for preparing based sensors as a family device in terms of lung cancer detection and the corresponding working mechanism would depend on the obvious and even sharp decrease in electrical resistance in $\mathrm{TiO}_{2}$-based sensors with respect to the results obtained from the healthy. Such devices would be quite simple and convenient because they only need the sample of exhaled gas of possible patients, which can be carried out in our daily life rather than in the hospital. 
In order to comprehensively understand the sensing mechanism of our proposed materials, the sensing experiment was conducted to confirm our theoretical study. Anatase $\mathrm{TiO}_{2}$ nanotubes were prepared by an anodic oxidation method; during this process, the $\mathrm{TiO}_{2}$ nanotubes could be uniformly electroplated onto the thin $\mathrm{Ti}$ slice to produce our film sensors. Gas-sensing properties of intrinsic anatase $\mathrm{TiO}_{2}$ nanotubes to analytes were implemented by electrochemical workstation. The whole experiment was performed under ambient temperature, with the sensing results shown in Figure 5 in which the vertical axis represents the responses $(R \%)$ that were calculated as the changing percentage of the resistance due to the exposure to the environment containing the target gas against the resistance measured without the presence of typical gases $\left(R_{0}=35.7 \Omega\right)$, while the horizontal axis represents the sensing time. After the sensing process to typical gases, the $\mathrm{N}_{2}$ was poured into the tank to refresh the environment; then, the related typical gas was poured again for repeated studies. We believed that in air with really large amount of $\mathrm{N}_{2}$, the recovery would be easily realized if the recovery could be fulfilled in our experiment. Based on Figure 5, we can found that $\mathrm{TiO}_{2}$ has the best sensitivity to $\mathrm{C}_{8} \mathrm{H}_{8}$ with the shortest sensing time and the strongest response, followed by $\mathrm{C}_{5} \mathrm{H}_{8}$ (the second) and $\mathrm{C}_{6} \mathrm{H}_{6}$ (the last). The sensing order of $\mathrm{TiO}_{2}$ towards the three kinds of typical gases was demonstrated by the theoretical study, suggesting their good accordance between experimental and theoretical methods. Specifically, the response time of $\mathrm{C}_{8} \mathrm{H}_{8}$ is the shortest about 1.5 minutes in the sensing stage, while it is about 2.5 minutes in the recovery stage. The $\mathrm{C}_{5} \mathrm{H}_{8}$ system has 2 minutes in the sensing stage and about 4 minutes in the recovery stage. The $\mathrm{C}_{6} \mathrm{H}_{6}$ shows the worst sensing performance with about 2 minutes of response time and 5 minutes of recovery time. One common thing is that all the three systems display a negative sensitivity, suggesting the reduced resistance after adsorption of typical gases compared with pure $\mathrm{TiO}_{2}$. This, as well, is in agreement with the previous theoretical study that adsorption of typical gases would lead to the increase in conductivity of $\mathrm{TiO}_{2}$ material.

Based on the above analysis, it is well found to conclude that $\mathrm{TiO}_{2}$, as it has good adsorption performance and sensing ability towards typical gases of lung cancer, could be a potential biomaterial for the application of making biosensors for the diagnosis of lung cancer as family-based devices. We strongly suggest the $\mathrm{TiO}_{2}$-based material for the future preparation of such device. Our study would be meaningful for further studies on the clinical test of such biosensor. Given the all reduced effects of adsorbing typical gases of lung cancer on the resistance of $\mathrm{TiO}_{2}$, the working principle of the biosensors would be based on the reduced resistance after the detection of exhaled air of possible lung cancer patients regardless of which kind of typical gas it is.

\section{Conclusions}

In this paper, on the basis of the density functional theory, the adsorption of the three typical exhaled gases of lung cancer patients, that is, benzene, styrene, and isoprene, on the anatase $\mathrm{TiO}_{2}$ (101) surface was simulated. The calculated results and analysis can provide theoretical foundation for the preparation of $\mathrm{TiO}_{2}$ nanotube array gas sensors because the $\mathrm{TiO}_{2}$ surface shows potential application as gas-sensing material to detect these three typical exhaled gases of lung cancer patients given the superior adsorbing performance. The related experiment was carried out to confirm the theoretical study as well, which has good consensus as expected. The conclusions are listed as follows:

(1) The anatase $\mathrm{TiO}_{2}$ (101) surface possesses certain sensitivity to benzene, styrene, and isoprene, and the sensitivity to styrene is the largest among the three gases.

(2) Frontier molecular orbital analyses illustrate that styrene possesses the highest active intensity among the three gases; that is to say, it is easier for styrene to transfer electrons and be adsorbed on the anatase $\mathrm{TiO}_{2}$ (101) surface in the adsorption process.

(3) Through comparing the energy gaps and DOS distributions of the insolated $\mathrm{TiO}_{2}$ (101) surface and three adsorbed systems, it can be found that the adsorption of these three gas molecules can reduce the energy gap of the anatase $\mathrm{TiO}_{2}$ (101) surface and therefore improve its conductive ability, leading to the enhanced conductivity of $\mathrm{TiO}_{2}$ after adsorbing any gas of the three typical gases.

(4) Performing as an $n$-type semiconductor, $\mathrm{TiO}_{2}$ nanotube arrays can be applied as gas-sensing material for the preparation of gas sensors to realize the prognosis of lung cancer in our daily life according to the obvious reduced electrical resistance with respect to the results obtained from the healthy.

(5) Given the great consensus between experimental and theoretical studies, the $\mathrm{TiO}_{2}$ could be a potential biosensor for the prognosis of lung cancer.

\section{Conflicts of Interest}

The authors declare that there is no conflict of interest regarding the publication of this paper.

\section{References}

[1] F. C. Detterbeck, S. Falen, M. P. Rivera, J. S. Halle, and M. A. Socinski, "Seeking a home for a PET, part 2," Chest, vol. 125, no. 6, pp. 2300-2308, 2004.

[2] Y. Ohno, H. Koyama, M. Nogami et al., "Postoperative lung function in lung cancer patients: comparative analysis of predictive capability of MRI, CT, and SPECT," American Journal of Roentgenology, vol. 189, no. 2, pp. 400-408, 2007.

[3] K. Yoshimoto, H. Nomori, T. Mori et al., "Prediction of pulmonary function after lung lobectomy by subsegments counting, computed tomography, single photon emission computed tomography and computed tomography: a comparative study," European Journal of Cardio-Thoracic Surgery, vol. 35, no. 3, pp. 408-413, 2009. 
[4] K. Zhang, R. An, Z. Gao, Y. Zhang, and M. R. Aruva, "Radionuclide imaging of small-cell lung cancer (SCLC) using 99m Tc-labeled neurotensin peptide 8-13," Nuclear Medicine and Biology, vol. 33, no. 4, pp. 505-512, 2006.

[5] S. M. Gordon, J. P. Szidon, B. K. Krotoszynski, R. D. Gibbons, and H. J. O'Neill, "Volatile organic compounds in exhaled air from patients with lung cancer," Clinical Chemistry, vol. 31, no. 8, pp. 1278-1282, 1985.

[6] M. Phillips, K. Gleeson, J. M. B. Hughes et al., "Volatile organic compounds in breath as markers of lung cancer: a crosssectional study," The Lancet, vol. 353, no. 9168, pp. 19301933, 1999.

[7] X. Zhang, H. Cui, D. Chen, X. Dong, and J. Tang, "Electronic structure and $\mathrm{H}_{2} \mathrm{~S}$ adsorption property of $\mathrm{Pt}_{3}$ cluster decorated $(8,0)$ SWCNT," Applied Surface Science, vol. 428, pp. 82-88, 2017.

[8] X. Zhang, H. Cui, Y. Gui, and J. Tang, "Mechanism and application of carbon nanotube sensors in $\mathrm{SF}_{6}$ decomposed production detection: a review," Nanoscale Research Letters, vol. 12, no. 1, p. $177,2017$.

[9] X. Zhang, H. Cui, J. Zhang, and J. Tang, "Adsorption characteristic of Pd-4 cluster carbon nanotube towards transformer oil dissolved components: a simulation," Applied Surface Science, vol. 419, pp. 802-810, 2017.

[10] L. Li and Y. Xing, "Pt-Ru nanoparticles supported on carbon nanotubes as methanol fuel cell catalysts," The Journal of Physical Chemistry C, vol. 111, no. 6, pp. 2803-2808, 2007.

[11] M. Penza, R. Rossi, M. Alvisi, D. Suriano, and E. Serra, "Pt-modified carbon nanotube networked layers for enhanced gas microsensors," Thin Solid Films, vol. 520, no. 3, pp. 959965, 2011.

[12] Y. Gönüllü, G. C. M. Rodríguez, B. Saruhan, and M. Ürgen, "Improvement of gas sensing performance of $\mathrm{TiO}_{2}$ towards $\mathrm{NO}_{2}$ by nano-tubular structuring," Sensors and Actuators B: Chemical, vol. 169, pp. 151-160, 2012.

[13] W. Göpel, G. Rocker, and R. Feierabend, "Intrinsic defects of $\mathrm{TiO}_{2}(110)$ : interaction with chemisorbed $\mathrm{O}_{2}, \mathrm{H}_{2}, \mathrm{CO}$, and $\mathrm{CO}_{2}$," Physical Review B, vol. 28, no. 6, pp. 3427-3438, 1983.

[14] C. H. Han, D. W. Hong, I. J. Kim, J. Gwak, S. D. Han, and K. C. Singh, "Synthesis of Pd or Pt/titanate nanotube and its application to catalytic type hydrogen gas sensor," Sensors and Actuators B: Chemical, vol. 128, no. 1, pp. 320-325, 2007.

[15] H. F. Lu, F. Li, G. Liu et al., "Amorphous $\mathrm{TiO}_{2}$ nanotube arrays for low-temperature oxygen sensors," Nanotechnology, vol. 19, no. 40, article 405504, 2008.

[16] X. Zhang, J. Zhang, Y. Jia, P. Xiao, and J. Tang, “ $\mathrm{TiO}_{2}$ nanotube array sensor for detecting the $\mathrm{SF}_{6}$ decomposition product $\mathrm{SO}_{2}$," Sensors, vol. 12, no. 12, pp. 3302-3313, 2012.

[17] Y. Zhang, W. Fu, H. Yang et al., "Synthesis and characterization of $\mathrm{TiO}_{2}$ nanotubes for humidity sensing," Applied Surface Science, vol. 254, no. 17, pp. 5545-5547, 2008.

[18] X. Zhang, J. Zhang, J. Tang, and B. Yang, "Gas-sensing simulation of single-walled carbon nanotubes applied to detect gas decomposition products of $\mathrm{SF}_{6}$," Journal of Computational and Theoretical Nanoscience, vol. 9, no. 8, pp. 1096-1100, 2012.

[19] X. Zhang, L. Yu, J. Tie, and X. Dong, "Gas sensitivity and sensing mechanism studies on Au-doped $\mathrm{TiO}_{2}$ nanotube arrays for detecting $\mathrm{SF}_{6}$ decomposed components," Sensors, vol. 14, no. 10, pp. 19517-19532, 2014.
[20] X. Zhang, Y. Gui, and Z. Dai, "Adsorption of gases from $\mathrm{SF}_{6}$ decomposition on aluminum-doped SWCNTs: a density functional theory study," The European Physical Journal D, vol. 69, no. 7, p. 185, 2015.

[21] J. X. Zhao and Y. H. Ding, "Theoretical study of the interactions of carbon monoxide with Rh-decorated $(8,0)$ singlewalled carbon nanotubes," Materials Chemistry and Physics, vol. 110, no. 2-3, pp. 411-416, 2008.

[22] N. T. Cuong, D. H. Chi, Y. T. Kim, and T. Mitani, "Structural and electronic properties of $\mathrm{Pt}_{n}(n=3,7,13)$ clusters on metallic single wall carbon nanotube," Physica Status Solidi, vol. 243, no. 13, pp. 3472-3475, 2006. 


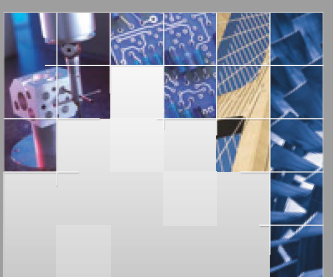

\section{Enfincering}
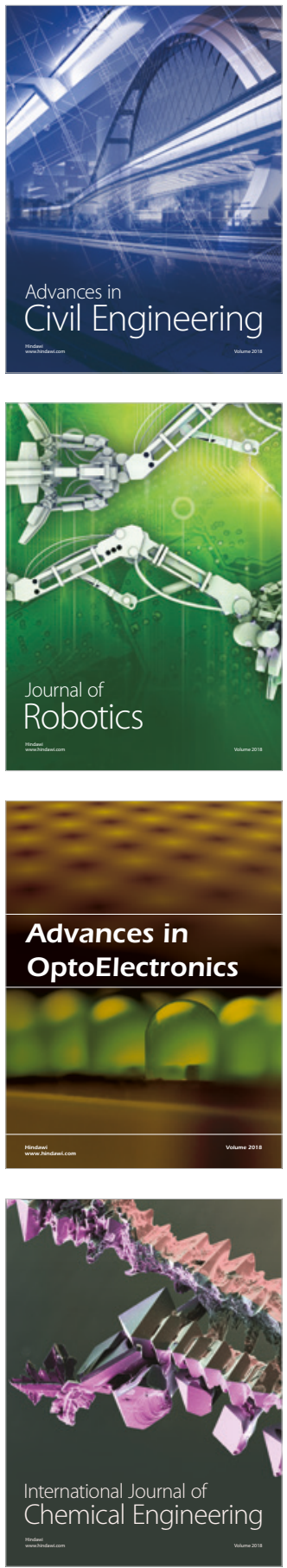

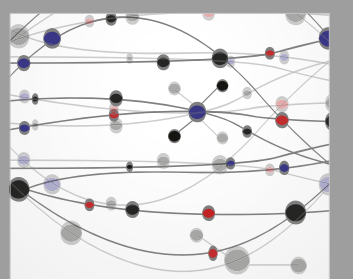

\section{Rotating \\ Machinery}

The Scientific World Journal

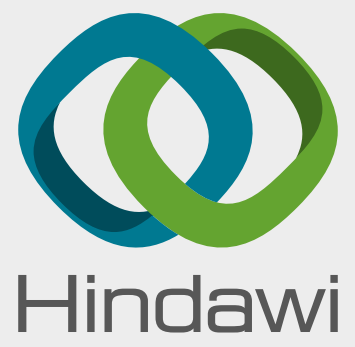

Submit your manuscripts at

www.hindawi.com
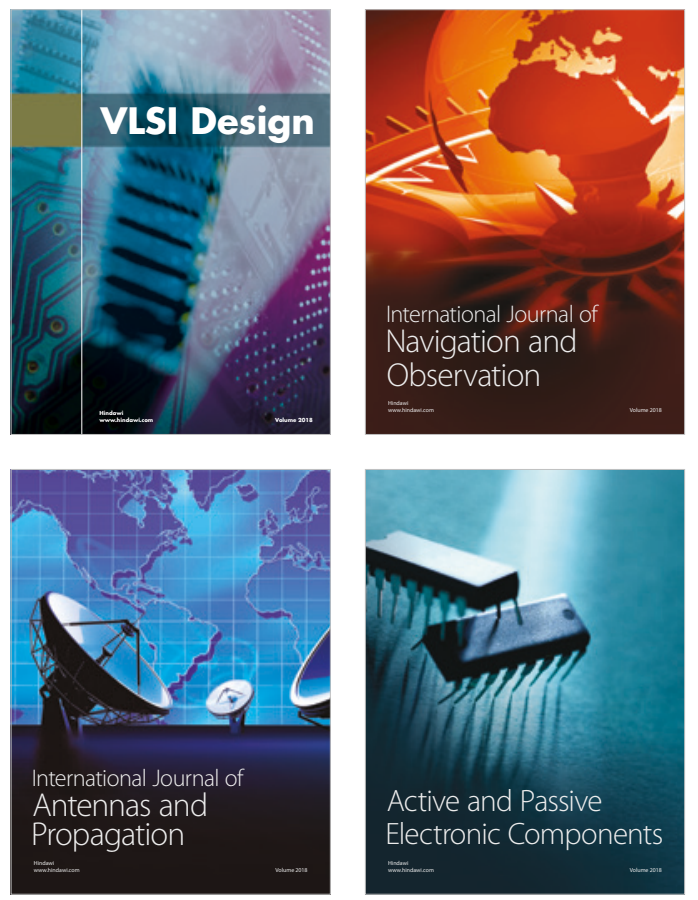
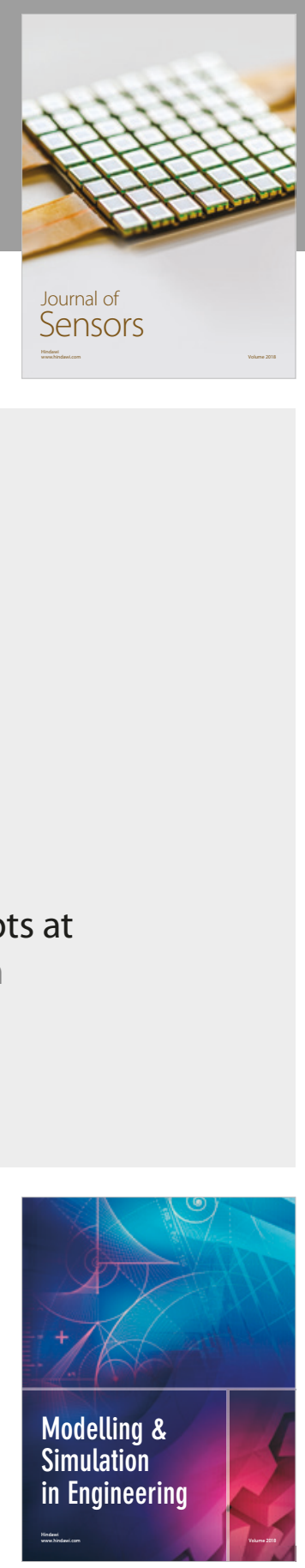

\section{Advances \\ Multimedia}
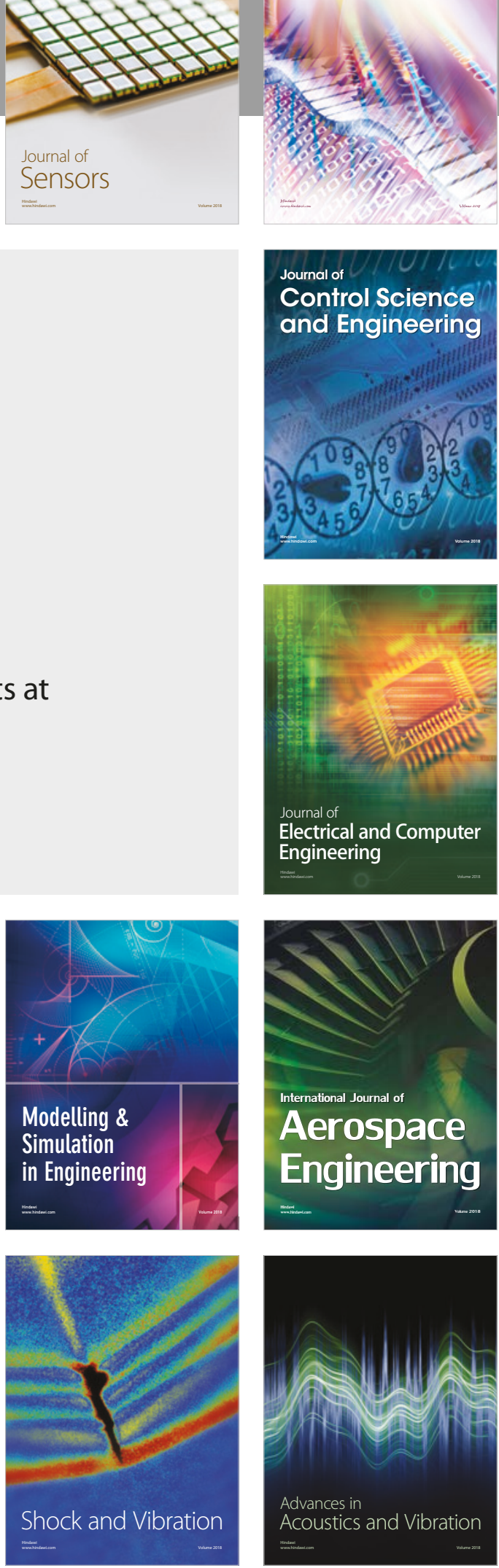